\title{
Maternal smoking during pregnancy and offspring growth in childhood: 1993 and 2004 Pelotas cohort studies
}

\author{
Alicia Matijasevich, Marie-Jo Brion, ${ }^{2}$ Ana M Menezes, ${ }^{1}$ Aluísio J D Barros, ${ }^{1}$ \\ Iná S Santos, ${ }^{1}$ Fernando C Barros ${ }^{3}$
}

1Postgraduate Programme in Epidemiology, Federal

University of Pelotas, Pelotas, Brazil

${ }^{2}$ Department of Social Medicine, University of Bristol, Bristol, UK

${ }^{3}$ Postgraduate Programme in Health and Behavior, Catholic University of Pelotas, Pelotas, Brazil

\section{Correspondence to}

Dr Alicia Matijasevich, Postgraduate Programme in Epidemiology, Federal University of Pelotas, Rua Marechal Deodoro 1160, 3rd floor, Pelotas, RS 96020-220, Brazil;

amatija@yahoo.com

Accepted 31 January 2011 Published Online First 3 March 2011

\begin{abstract}
Objective To explore the effects of maternal smoking during pregnancy on offspring growth using three approaches: (1) multiple adjustments for socioeconomic and parental factors, (2) maternalpaternal comparisons as a test of putative intrauterine effects and (3) comparisons between two birth cohort studies.

Methods Population-based birth cohort studies were carried out in Pelotas, Brazil, in 1993 and 2004. Cohort members were followed up at 3, 12, 24 and 48 months. Multiple linear regression analysis was used to examine the relationships between maternal and paternal prenatal smoking and offspring anthropometric indices. In the 2004 cohort, the association of smoking with trunk length, leg length and leg-to-sitting-height ratio at 48 months was also explored.

Results Maternal smoking during pregnancy was associated with reduced $z$ scores of length/height-forage at each follow-up in both cohorts and reduced leg length at 48 months in the 2004 cohort. Children older than 3 months born to smoking women showed a higher body mass index-for-age $z$ score than children of nonsmoking women.
\end{abstract}

Conclusions The results of this study strongly support the hypothesis that maternal smoking during pregnancy impairs linear growth and promotes overweight in childhood.

\section{INTRODUCTION}

It is generally accepted that maternal smoking during pregnancy is associated with reduced offspring weight, height and head circumference at birth. ${ }^{12}$ However, the literature on prenatal smoking and postnatal growth is less consistent. Studies following up children born to women who smoked during pregnancy suggest that deficits in weight and height observed at birth may persist in childhood and possibly even into adulthood. ${ }^{3-5}$ Prenatal smoking has also been associated with height components, particularly with leg length, ${ }^{6}$ which is especially sensitive to environmental factors in early childhood. ${ }^{7}$ Not all studies, however, support the finding of long-term detrimental effects of prenatal smoking on offspring weight or height. ${ }^{89}$

Overweight and obesity have reached epidemic proportions worldwide. In many countries, including the USA, the UK, Australia, China and Brazil, child overweight is increasing at a faster rate than adult obesity. ${ }^{10}$ There is evidence of tracking of overweight, with overweight children having a high risk of being overweight later in life. ${ }^{11}$

\section{What is already known on this topic}

- Maternal smoking during pregnancy is associated with reduced offspring weight, height and head circumference at birth.

- The findings of long-term detrimental effects of maternal smoking during pregnancy on offspring postnatal growth are inconsistent.

\section{What this study adds}

- This study strongly suggests a possible causal effect of maternal smoking during pregnancy on offspring impaired linear growth and overweight in childhood via intrauterine mechanisms.

- Our findings accentuate the importance of advising women on smoking cessation to prevent the long-term deleterious effect of maternal smoking during pregnancy on child growth

Furthermore, several studies showed an increased prevalence of overweight and obesity in childhood in offspring of women who smoked during pregnancy ${ }^{12-15}$ and a recent meta-analyses strengthened these findings. ${ }^{16}$

Most of the studies that investigated the effects of maternal smoking during pregnancy on offspring growth during childhood have used data from high-income countries where confounding structures may differ from populations of low and middle-income countries. ${ }^{17}$ In addition, few of these studies have examined associations with paternal smoking to explore whether maternal smoking is of specific importance.

The objective of this study is to explore the effects of maternal smoking during pregnancy on offspring growth using three approaches: (1) multiple adjustments for socioeconomic and parental factors, (2) maternal-paternal comparisons as a test of putative intrauterine effects and (3) comparisons between two middle-income country birth cohort studies, the 1993 and 2004 Pelotas cohorts, in Brazil.

\section{METHODS}

\section{Research setting and study design}

During 1993 and 2004, birth cohort studies of all births to mothers living in urban areas of the city 
of Pelotas, in Southern Brazil, were carried out with primary data collection and using almost the same methodology (5304 and 4287 births in the 1993 and 2004 cohorts, respectively). The non-response rate at recruitment in both cohorts was below 1\%. A detailed description of the methodology is given elsewhere. ${ }^{18} 19$ Soon after delivery, mothers were interviewed using a pretested structured questionnaire and their newborns were examined by specially trained interviewers under the supervision of a paediatrician.

In the 1993 cohort, a systematic sample of $13 \%$ of the cohort participants was followed up at home at 3 months ( 655 infants). At 12 and 48 months, a more complex sampling scheme was used: all low birthweight children plus $20 \%$ of the remainder, including those visited at 3 months, were visited at home (1460 and 1450 children, respectively). In the 2004 cohort study, all cohort children were followed up when they were 3,12 , 24 and 48 months old (3985, 3907, 3869 and 3799 children, respectively). On each occasion, mothers were interviewed by trained field workers and their children were weighed and measured.

\section{Outcome measures and covariates}

Birth weight was measured by hospital staff with precision paediatric scales accurate to $10 \mathrm{~g}$ that were regularly calibrated by the research team. Supine length measurements were taken using ARTHAG infantometers (AHRTAG, London, $\mathrm{UK}){ }^{20}$ Estimates of gestational age were based on the last menstrual period (LMP) providing they were consistent with predicted birth weight, length and head circumference, based on the normal curves for these parameters for each week of gestational age. ${ }^{21}$ If LMP-based gestational age was unknown or inconsistent, we adopted the clinical maturity estimate based on the Dubowitz method, ${ }^{22}$ which was performed on all newborns.

At each follow-up, anthropometric measurements were performed by trained interviewers with the children dressed in underwear and barefoot. When clothing was worn, these items were noted and their weights subsequently deducted from the child's measured weight. In the 1993 cohort study, children were weighed using Salter CMS mechanical scales (Salter, Tonbridge, UK) with a $25 \mathrm{~kg}$ maximum and $100 \mathrm{~g}$ precision. Tanita electronic scales (Tanita, Arlington Heights, Illinois, USA) with a $150 \mathrm{~kg}$ maximum and $100 \mathrm{~g}$ precision were used in the 2004 cohort study. In both studies, scales were calibrated on a weekly basis using standard weights. Recumbent length (children $\leq 24$ months of age), standing height (48 months of age) and sitting height of the child (48 months of age, only for 2004 cohort children) were measured using a portable infantometer with $1 \mathrm{~mm}$ precision, custom built for these studies. Leg length was derived by subtracting sitting height (in $\mathrm{cm}$ ) from standing height (in $\mathrm{cm}$ ). The leg-to-sitting-height ratio was calculated by dividing leg length by sitting height, and multiplying by 100. Sitting height will be referred as trunk length in all analyses. Head circumference was measured using inelastic tape measures with $1 \mathrm{~mm}$ precision.

Based on the collected data, we calculated $z$ scores for length-for-age, weight-for-age, weight-for-length/height, head circumference-for-age and body mass index (BMI)-for-age among offspring according to the growth curves published by $\mathrm{WHO}$ in $2006 .^{23}$ The anthropometric indices, trunk length, leg length and leg-to-sitting-height ratio each constituted the outcomes of the study, while maternal and paternal smoking during pregnancy were the main exposures.
Maternal and paternal smoking behaviours during pregnancy were assessed retrospectively at birth and were based on the mother's report. Regular smokers were those women or their partners who smoked at least one cigarette every day in any trimester of pregnancy.

Information on possible confounding factors was gathered from the perinatal interview. Infant sex was recorded at birth. Family income in the month prior to delivery was collected as a continuous variable (in Reais) and analysed as quintiles. Mother's skin colour was self-reported and categorised as white or black/mixed. Maternal formal education was categorised as $0-4,5-8$ and $\geq 9$ complete school years. Women who were single, widowed, divorced or lived without a partner were classified as single mothers. Maternal age in complete years was categorised as $\leq 19,20-34$ and $\geq 35$ years. Parity was defined as the number of previous viable pregnancies and categorised as 0,1 and $\geq 2$. Maternal height was measured using a aluminium stadiometer with $1 \mathrm{~mm}$ precision. Prepregnancy weight was obtained from prenatal records at the woman's first antenatal visit or, in their absence, by maternal recall at the time of delivery. Maternal height (m), prepregnancy BMI $\left(\mathrm{kg} / \mathrm{m}^{2}\right)$ and gestational age (weeks) were included in the analyses as continuous variables.

\section{Statistical analysis}

We used tests for linear trends and $\chi^{2}$ tests to compare the distribution of maternal and paternal smoking during pregnancy by maternal characteristics. Multiple linear regression analysis was used to examine the relationships between maternal and paternal smoking and offspring anthropometric indexes, trunk length, leg length and leg-to-trunk ratio using models unadjusted and adjusted for potential confounding factors. Analyses were explored first for maternal and paternal smoking individually, followed by mutually adjusted models of maternal and paternal smoking adjusted for one another. Potential effect modification by paternal smoking on the association between maternal smoking during pregnancy and each offspring's anthropometric index was investigated in each cohort study. Child's age at the time of height measurement and sex were included in the adjusted analyses of the association between trunk length, leg length and leg-to-trunk ratio and maternal and paternal smoking status.

Analyses of the 1993 cohort were weighted to correct for the over-sampling of low birthweight babies. All analyses were performed using Stata 11.0.

The study protocol was approved by the Medical Ethics Committee of the Federal University of Pelotas, affiliated with the Brazilian Federal Medical Council. Oral consent (1993 cohort study) and oral and written informed consent (2004 cohort study) were obtained from women who agreed to participate in the study.

\section{RESULTS}

In the 1993 cohort study, $33.5 \%$ of mothers and $44.8 \%$ of fathers smoked during pregnancy. In 2004, the prevalence of prenatal smoking was $28 \%$ among mothers and $31 \%$ among fathers. Over the 11-year period, the prevalence of maternal and paternal prenatal smoking declined, however, this reduction was larger among fathers than among mothers $(31 \%$ vs $16 \%$ for fathers and mothers, respectively).

In both cohort studies, maternal smoking during pregnancy was more likely among poorer, less educated mothers. Smoking mothers were more likely to be shorter, heavier 
Table 1 Parental smoking during pregnancy according to maternal characteristics, Pelotas 1993 and 2004 birth cohort studies

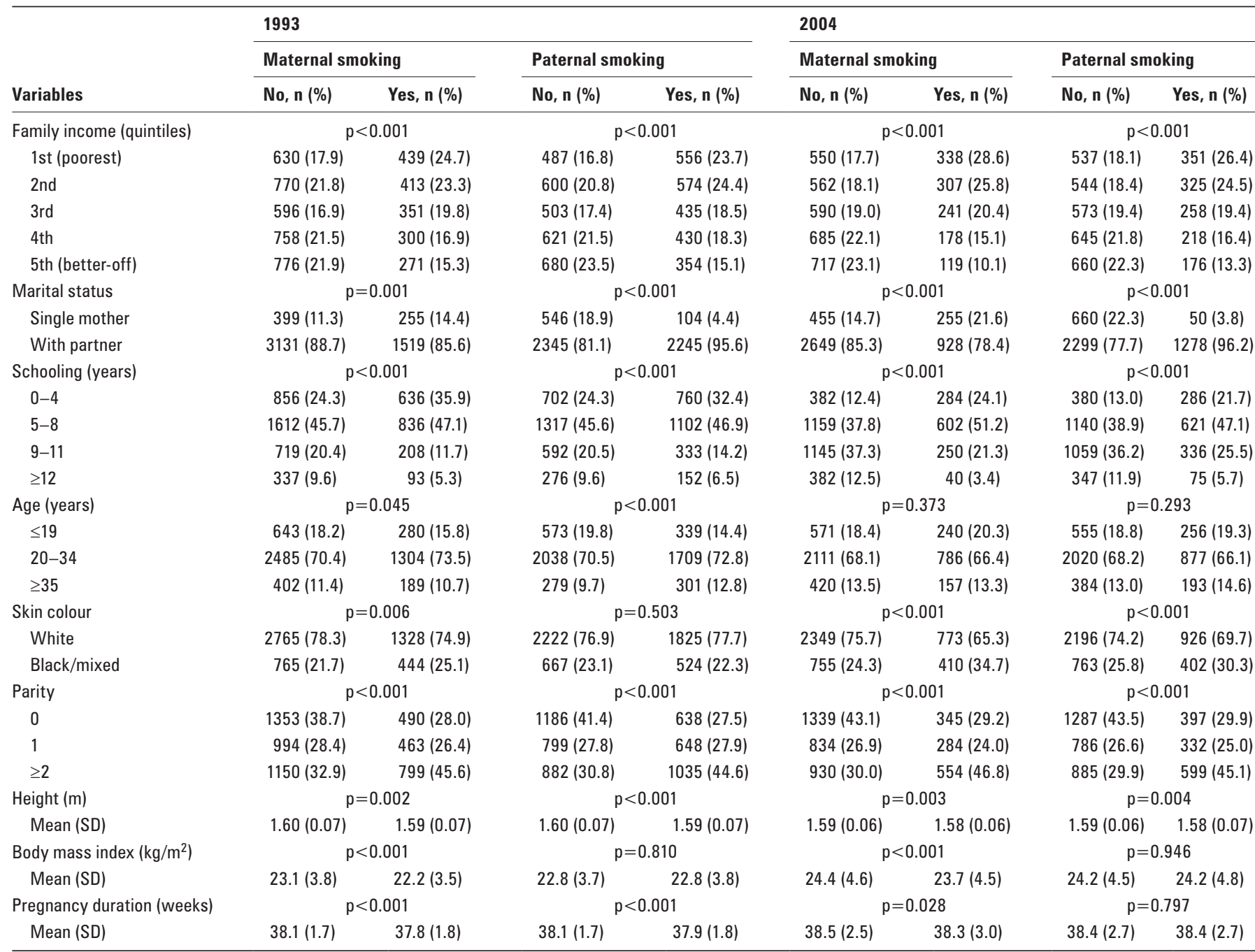

and to have offspring of lower gestational age at delivery (table 1). Maternal smoking was also more likely among mothers of black/mixed ethnic origin. In the 1993 Pelotas cohort, the prevalence of smoking was lower among adolescent mothers.

Paternal smoking during pregnancy was more frequently seen among the poorest women, among those less educated, shorter and multiparous (table 1). In the 1993 Pelotas cohort study, paternal smoking status was not associated with maternal skin colour or maternal prepregnancy BMI. There was no association between paternal smoking status and maternal age, prepregnancy BMI or pregnancy duration in the 2004 Pelotas cohort study (table 1).

In unadjusted analyses (tables 2 and 3), maternal smoking in pregnancy in both cohorts was associated with lower offspring weight, length and head circumference at every follow-up, and with lower BMI at birth only. In fully adjusted analyses (adjusted for maternal characteristics, pregnancy duration and paternal smoking), maternal smoking in pregnancy was associated with lower offspring length at every follow-up and was associated with lower offspring BMI at birth but higher BMI at follow-ups at 12 months and older. While maternal smoking in adjusted analyses was consistently (in both cohorts) associated with lower offspring weight and head circumference at birth, this was not observed at later follow-ups, except for head circumference at 3 months in the 2004 cohort.
Statistical differences between the adjusted maternal and paternal associations were found for offspring length at every follow-up, weight at birth, BMI at birth and at follow-ups at 12 months and older and head circumference at birth.

No evidence of interaction between maternal and paternal smoking on any offspring outcome was found in the 1993 and 2004 cohort studies.

Maternal prenatal smoking was associated with a reduction in offspring trunk length, leg length and leg-to-trunk ratio at 48 months in the 2004 cohort, after adjustment for the child's age at the time of measurement and sex (table 4). Although additional adjustment for maternal factors, pregnancy duration and paternal smoking during pregnancy weakened associations, maternal prenatal smoking was still related to leg length and leg-to-trunk ratio. The associations between paternal smoking and trunk length, leg length and leg-to-trunk ratio were considerably weaker than those for maternal smoking and disappeared after adjustment for confounders. No differences were found between the sexes.

\section{DISCUSSION}

The present study found evidence of maternal-specific effects of smoking during pregnancy on child's growth. Consistent results were observed between the 1993 and 2004 Pelotas cohort studies, showing that even after adjustment for potential confounding factors, offspring of women who smoked 
Table 2 Crude and adjusted analyses of child's z score of weight-for-age (W/A), length or height-for-age ( $(\mathrm{A} / \mathrm{A}$ or $\mathrm{H} / \mathrm{A})$, body mass index-for-age (BMI/A) and head circumference-for-age $(\mathrm{HC} / \mathrm{A})$ at each follow-up according to maternal and paternal smoking during pregnancy, 1993 Pelotas cohort study

\begin{tabular}{|c|c|c|c|c|}
\hline z Score & Crude coefficient (95\% CI) & p Value & Adjusted coefficient (95\% CI) & $\mathrm{p}$ Value \\
\hline \multicolumn{5}{|l|}{ Maternal smoking } \\
\hline W/A at birth & $-0.43(-0.50$ to -0.37$)$ & $<0.001$ & $-0.28(-0.34 \text { to }-0.22)^{*}$ & $<0.001 \dagger$ \\
\hline 3 months & $-0.33(-0.49$ to -0.16$)$ & $<0.001$ & $-0.13(-0.31 \text { to } 0.04)^{*}$ & 0.138 \\
\hline 12 months & $-0.18(-0.31$ to -0.05$)$ & 0.009 & $0.05(-0.09 \text { to } 0.19)^{*}$ & 0.472 \\
\hline 48 months & $-0.26(-0.41$ to -0.12$)$ & $<0.001$ & $0.01(-0.14 \text { to } 0.16)^{*}$ & 0.902 \\
\hline $\mathrm{L} / \mathrm{A}$ at birth & $-0.45(-0.52$ to -0.38$)$ & $<0.001$ & $-0.34(-0.40 \text { to }-0.27)^{*}$ & $<0.001 \dagger$ \\
\hline 3 months & $-0.61(-0.80$ to -0.42$)$ & $<0.001$ & $-0.35(-0.56 \text { to }-0.15)^{*}$ & $0.001 \dagger$ \\
\hline 12 months & $-0.49(-0.63$ to -0.34$)$ & $<0.001$ & $-0.20(-0.35 \text { to }-0.05)^{*}$ & $0.009 \dagger$ \\
\hline $\mathrm{H} / \mathrm{A}$ at 48 months & $-0.47(-0.61$ to -0.34$)$ & $<0.001$ & $-0.21(-0.35 \text { to }-0.08)^{*}$ & $0.002 \dagger$ \\
\hline BMI/A at birth & $-0.32(-0.38$ to -0.25$)$ & $<0.001$ & $-0.19(-0.25 \text { to }-0.12)^{*}$ & $<0.001 \dagger$ \\
\hline 3 months & $0.04(-0.14$ to 0.22$)$ & 0.654 & $0.10(-0.08 \text { to } 0.29)^{*}$ & 0.278 \\
\hline 12 months & $0.14(0.01$ to 0.26$)$ & 0.032 & $0.23(0.09 \text { to } 0.36)^{*}$ & $0.001 \dagger$ \\
\hline 48 months & $0.02(-0.13$ to 0.16$)$ & 0.825 & $0.17(0.02 \text { to } 0.32)^{*}$ & $0.028 t$ \\
\hline $\mathrm{HC} / \mathrm{A}$ at birth & $-0.39(-0.46$ to -0.32$)$ & $<0.001$ & $-0.25(-0.32 \text { to }-0.18)^{*}$ & $<0.001 \dagger$ \\
\hline 3 months & $-0.33(-0.51$ to -0.15$)$ & $<0.001$ & $-0.13(-0.33 \text { to } 0.06)^{*}$ & 0.173 \\
\hline 12 months & $-0.20(-0.34$ to -0.06$)$ & 0.005 & $-0.01(-0.16 \text { to } 0.14)^{*}$ & 0.906 \\
\hline \multicolumn{5}{|l|}{ Paternal smoking } \\
\hline W/A at birth & $-0.16(-0.23$ to -0.10$)$ & $<0.001$ & $-0.05(-0.11$ to 0.01$) \ddagger$ & $0.085 \dagger$ \\
\hline 3 months & $-0.23(-0.40$ to -0.07$)$ & 0.004 & $-0.09(-0.25$ to 0.07$) \ddagger$ & 0.285 \\
\hline 12 months & $-0.22(-0.34$ to -0.10$)$ & 0.001 & $-0.10(-0.23$ to 0.03$) \ddagger$ & 0.121 \\
\hline 48 months & $-0.26(-0.40$ to -0.13$)$ & $<0.001$ & $-0.09(-0.24$ to 0.05$) \ddagger$ & 0.207 \\
\hline $\mathrm{L} / \mathrm{A}$ at birth & $-0.14(-0.20$ to -0.07$)$ & $<0.001$ & $-0.01(-0.08$ to 0.05$) \ddagger$ & $0.711 \dagger$ \\
\hline 3 months & $-0.26(-0.45$ to -0.06$)$ & 0.009 & $-0.04(-0.23$ to 0.16$) \ddagger$ & $0.710 \dagger$ \\
\hline 12 months & $-0.28(-0.43$ to -0.13$)$ & $<0.001$ & $-0.08(-0.22$ to 0.07$) \ddagger$ & $0.299 \dagger$ \\
\hline $\mathrm{H} / \mathrm{A}$ at 48 months & $-0.26(-0.39$ to -0.12$)$ & $<0.001$ & $-0.03(-0.16$ to 0.11$) \ddagger$ & $0.706 \dagger$ \\
\hline $\mathrm{BMI} / \mathrm{A}$ at birth & $-0.14(-0.21$ to -0.08$)$ & $<0.001$ & $-0.079(-0.14$ to -0.02$) \ddagger$ & $0.014 \dagger$ \\
\hline 3 months & $-0.11(-0.27$ to 0.05$)$ & 0.168 & $-0.087(-0.25$ to 0.08$) \ddagger$ & 0.298 \\
\hline 12 months & $-0.08(-0.20$ to 0.04$)$ & 0.184 & $-0.073(-0.20$ to 0.05$) \ddagger$ & $0.252 \dagger$ \\
\hline 48 months & $-0.14(-0.28$ to 0.01$)$ & 0.051 & $-0.092(-0.24$ to 0.05$) \ddagger$ & $0.216 \dagger$ \\
\hline $\mathrm{HC} / \mathrm{A}$ at birth & $-0.15(-0.22$ to -0.07$)$ & $<0.001$ & $-0.04(-0.11$ to 0.02$) \ddagger$ & $0.215 \dagger$ \\
\hline 3 months & $-0.29(-0.47$ to -0.12$)$ & 0.001 & $-0.19(-0.36$ to -0.01$) \ddagger$ & 0.035 \\
\hline 12 months & $-0.20(-0.33$ to -0.07$)$ & 0.003 & $-0.09(-0.22$ to 0.05$) \ddagger$ & 0.212 \\
\hline
\end{tabular}

${ }^{*}$ Adjusted for family income, marital status, schooling, age, skin colour, parity, height, body mass index (BMI), pregnancy duration and paternal smoking.

$t \chi^{2}$ Test $p<0.05$ for difference between maternal and paternal coefficients in the adjusted analysis.

$\ddagger$ Adjusted for family income, marital status, schooling, age, skin colour, parity, height, BMI, pregnancy duration and maternal smoking.

during pregnancy had persistent reductions in length/height at repeated follow-ups from birth to 48 months, had shorter leg length at 48 months, and had higher BMI-for-age z scores at follow-ups at 12 months and older than children of nonsmokers. The magnitude of maternal smoking effects on child's growth was greater than and significantly different from paternal smoking effects.

Several prenatal and postnatal factors influence childhood height. $^{24-27}$ Childhood height is the best predictor of adult height, which is associated with adult health and human capital. ${ }^{28}$ Leg length growth contributes markedly to stature attainment and is highly influenced by environmental factors in early childhood. ${ }^{7}$ In our study, consistent reductions in offspring height and height components (in particular leg length and leg-to-trunk ratio) were seen among offspring of women who smoked during pregnancy, findings that have also been reported by Leary et $a^{6}$ at 7.5 years in the Avon Longitudinal Study of Parents and Children. Although there is some evidence in the literature that the effects of maternal smoking during pregnancy on offspring height decrease with greater offspring age, ${ }^{29}$ this was not observed in the present study.
However, follow-up was limited here to 48 months after birth. Therefore, analyses of future follow-ups in the 2004 cohort will enable further exploration of the long-term effects of maternal prenatal smoking on offspring height.

Smoking is a strongly socially patterned behaviour, thus it is possible that the association between maternal prenatal smoking and child height is due to confounding by wider socioeconomic factors. Although associations attenuated after adjustment for possible confounders, persisting associations were still observed. Furthermore, the markedly discordant maternal-paternal associations observed suggests that maternal smoking during pregnancy may have specific intrauterine effects on offspring height and that residual confounding may be a less likely explanation. Indeed, studies have reported embryotoxic effects of nicotine or other toxic pollutants found in cigarette smoke that lead to delayed skeletal growth. ${ }^{30}$

Our findings support previous work showing that reductions in weight at birth in children born to mothers who smoke during pregnancy are overcome in infancy. ${ }^{9}$ The combination of weight being recovered and persisting deficits in height could result in greater body mass in children of maternal smokers. In 
Table 3 Crude and adjusted analyses of child's z score of weight-for-age (W/A), length or height-for-age ( $\mathrm{L} / \mathrm{A}$ or $\mathrm{H} / \mathrm{A})$, body mass index-for-age (BMI/A) and head circumference-for-age (HC/A) at each follow-up according to maternal and paternal smoking during pregnancy, 2004 Pelotas cohort study

\begin{tabular}{|c|c|c|c|c|}
\hline z Score & Crude coefficient (95\% CI) & p Value & Adjusted coefficient (95\% CI) & p Value \\
\hline \multicolumn{5}{|l|}{ Maternal smoking } \\
\hline W/A at birth & $-0.32(-0.40$ to -0.23$)$ & $<0.001$ & $-0.32(-0.41 \text { to }-0.22)^{*}$ & $<0.001 \dagger$ \\
\hline 3 months & $-0.25(-0.34$ to -0.17$)$ & $<0.001$ & $-0.13(-0.21 \text { to }-0.05)^{*}$ & 0.003 \\
\hline 12 months & $-0.13(-0.21$ to -0.06$)$ & $<0.001$ & $0.03(-0.06 \text { to } 0.11)^{*}$ & 0.565 \\
\hline 24 months & $-0.23(-0.31$ to -0.15$)$ & $<0.001$ & $-0.03(-0.12 \text { to } 0.05)^{*}$ & 0.409 \\
\hline 48 months & $-0.27(-0.36$ to -0.19$)$ & $<0.001$ & $-0.02(-0.11 \text { to } 0.07)^{*}$ & 0.647 \\
\hline $\mathrm{L} / \mathrm{A}$ at birth & $-0.28(-0.36$ to -0.20$)$ & $<0.001$ & $-0.24(-0.33 \text { to }-0.16)^{*}$ & $<0.001 \dagger$ \\
\hline 3 months & $-0.36(-0.44$ to -0.27$)$ & $<0.001$ & $-0.24(-0.32 \text { to }-0.15)^{*}$ & $<0.001 \dagger$ \\
\hline 12 months & $-0.36(-0.44$ to -0.28$)$ & $<0.001$ & $-0.20(-0.28 \text { to }-0.11)^{*}$ & $<0.001 \dagger$ \\
\hline 24 months & $-0.42(-0.50$ to -0.34$)$ & $<0.001$ & $-0.20(-0.28 \text { to }-0.12)^{*}$ & $<0.001 \dagger$ \\
\hline $\mathrm{H} / \mathrm{A}$ at 48 months & $-0.39(-0.47$ to -0.32$)$ & $<0.001$ & $-0.19(-0.26 \text { to }-0.11)^{*}$ & $<0.001 \dagger$ \\
\hline $\mathrm{BMI} / \mathrm{A}$ at birth & $-0.26(-0.340$ to -0.19$)$ & $<0.001$ & $-0.27(-0.37 \text { to }-0.16)^{*}$ & $<0.001 \dagger$ \\
\hline 3 months & $-0.08(-0.16$ to -0.01$)$ & 0.036 & $-0.05(-0.16 \text { to } 0.05)^{*}$ & 0.321 \\
\hline 12 months & 0.10 (0.03 to 0.18$)$ & 0.007 & $0.20(0.11 \text { to } 0.28)^{*}$ & $<0.001 \dagger$ \\
\hline 24 months & $0.03(-0.04$ to 0.11$)$ & 0.348 & $0.12(0.04 \text { to } 0.20)^{*}$ & $0.005 \dagger$ \\
\hline 48 months & $-0.07(-0.16$ to 0.01$)$ & 0.090 & $0.10(0.01 \text { to } 0.19)^{*}$ & 0.039 \\
\hline $\mathrm{HC} / \mathrm{A}$ at birth & $-0.31(-0.40$ to -0.22$)$ & $<0.001$ & $-0.23(-0.32 \text { to }-0.15)^{*}$ & $<0.001 \dagger$ \\
\hline 3 months & $-0.25(-0.32$ to -0.17$)$ & $<0.001$ & $-0.15(-0.23 \text { to }-0.07)^{*}$ & $<0.001 \dagger$ \\
\hline 12 months & $-0.18(-0.25$ to -0.10$)$ & $<0.001$ & $-0.04(-0.12 \text { to } 0.04)^{*}$ & 0.310 \\
\hline 24 months & $-0.20(-0.28$ to -0.13$)$ & $<0.001$ & $-0.07(-0.15 \text { to } 0.01)^{*}$ & 0.094 \\
\hline 48 months & $-0.22(-0.30$ to -0.15$)$ & $<0.001$ & $-0.06(-0.15 \text { to } 0.02)^{*}$ & 0.146 \\
\hline \multicolumn{5}{|l|}{ Paternal smoking } \\
\hline W/A at birth & $0.11(-0.19$ to -0.03$)$ & 0.008 & $-0.05(-0.14$ to 0.04$) \ddagger$ & $0.265 \dagger$ \\
\hline 3 months & $-0.14(-0.22$ to -0.06$)$ & $<0.001$ & $-0.06(-0.14$ to 0.02$) \ddagger$ & 0.140 \\
\hline 12 months & $-0.14(-0.22$ to -0.06$)$ & $<0.001$ & $-0.06(-0.14$ to 0.02$) \ddagger$ & 0.143 \\
\hline 24 months & $-0.17(-0.25$ to -0.10$)$ & $<0.001$ & $-0.03(-0.11$ to 0.05$) \ddagger$ & 0.496 \\
\hline 48 months & $-0.21(-0.30$ to -0.13$)$ & $<0.001$ & $-0.05(-0.14$ to 0.04$) \ddagger$ & 0.262 \\
\hline $\mathrm{L} / \mathrm{A}$ at birth & $-0.07(-0.15$ to 0.01$)$ & 0.106 & $0.02(-0.06$ to 0.10$) \ddagger$ & $0.614 \dagger$ \\
\hline 3 months & $-0.16(-0.24$ to -0.07$)$ & $<0.001$ & $-0.02(-0.11$ to 0.06$) \ddagger$ & $0.543 \dagger$ \\
\hline 12 months & $-0.20(-0.28$ to -0.12$)$ & $<0.001$ & $-0.04(-0.12$ to 0.04$) \ddagger$ & $0.276 \dagger$ \\
\hline 24 months & $-0.25(-0.33$ to -0.17$)$ & $<0.001$ & $-0.04(-0.12$ to 0.04$) \ddagger$ & $0.317 \dagger$ \\
\hline $\mathrm{H} / \mathrm{A}$ at 48 months & $-0.24(-0.31$ to -0.17$)$ & $<0.001$ & $-0.04(-0.12$ to 0.03$) \ddagger$ & $0.239 \dagger$ \\
\hline $\mathrm{BMI} / \mathrm{A}$ at birth & $-0.10(-0.18$ to -0.03$)$ & 0.007 & $-0.07(-0.16$ to 0.03$) \ddagger$ & $0.169 \dagger$ \\
\hline 3 months & $-0.09(-0.17$ to -0.02$)$ & 0.011 & $-0.13(-0.23$ to -0.03$) \ddagger$ & 0.008 \\
\hline 12 months & $-0.03(-0.10$ to 0.04$)$ & 0.363 & $-0.05(-0.13$ to 0.03$) \ddagger$ & $0.197 \dagger$ \\
\hline 24 months & $-0.03(-0.10$ to 0.04$)$ & 0.363 & $-0.01(-0.09$ to 0.07$) \ddagger$ & $0.799 \dagger$ \\
\hline 48 months & $-0.09(-0.17$ to -0.01$)$ & 0.034 & $-0.04(-0.12$ to 0.05$) \ddagger$ & 0.440 \\
\hline $\mathrm{HC} / \mathrm{A}$ at birth & $-0.13(-0.21$ to -0.04$)$ & 0.003 & $-0.01(-0.10$ to 0.07$) \ddagger$ & $0.751 \dagger$ \\
\hline 3 months & $-0.14(-0.21$ to -0.06$)$ & $<0.001$ & $-0.03(-0.10$ to 0.05$) \ddagger$ & $0.449 \dagger$ \\
\hline 12 months & $-0.16(-0.23$ to -0.09$)$ & $<0.001$ & $-0.05(-0.13$ to 0.02$) \ddagger$ & 0.174 \\
\hline 24 months & $-0.17(-0.24$ to -0.10$)$ & $<0.001$ & $-0.04(-0.12$ to 0.04$) \ddagger$ & 0.307 \\
\hline 48 months & $-0.19(-0.27$ to -0.12$)$ & $<0.001$ & $-0.06(-0.14$ to 0.02$) \ddagger$ & 0.162 \\
\hline
\end{tabular}

${ }^{*}$ Adjusted for family income, marital status, schooling, age, skin colour, parity, height, body mass index (BMI), pregnancy duration and paternal smoking.

$t \chi^{2}$ Test $\mathrm{p}<0.05$ for difference between maternal and paternal coefficients in the adjusted analysis.

$\ddagger$ Adjusted for family income, marital status, schooling, age, skin colour, parity, height, BMI, pregnancy duration and maternal smoking.

our study higher BMI z scores were seen among the offspring of women who smoked during pregnancy. Our results are in line with previous studies that reported the association between maternal smoking during pregnancy and childhood overweight and obesity, ${ }^{12} 16$ and several hypotheses have been postulated to explain this relationship. ${ }^{31}$ The persistence of the association between maternal prenatal smoking and offspring BMI z scores after adjustment for possible confounders, the discordant maternal-paternal associations observed and the consistency of the findings between the 1993 and 2004 Pelotas cohort studies again make confounding a less likely explanation.
We found a specific negative effect of maternal smoking on head circumference at birth. Our results showed that this association is independent of the relationship between premature birth and maternal smoking. However, deficits in head circumference did not persist in infancy, as also shown in other studies. ${ }^{4} 8$

A major strength of the present study was the method of data collection (prospective information obtained among large unselected populations and comparable timescales) combined with the use of standardised anthropometric measurements performed by trained fieldworkers, high follow-up rates and 
Table 4 Regressions of offspring trunk length, leg length and leg-to-trunk ratio at 48 months on maternal and paternal smoking during pregnancy in 2004 Pelotas birth cohort children

\begin{tabular}{|c|c|c|c|c|c|c|}
\hline & \multicolumn{2}{|l|}{ Trunk length (cm) } & \multicolumn{2}{|l|}{ Leg length $(\mathrm{cm})$} & \multicolumn{2}{|l|}{ Leg/trunk (\%) } \\
\hline & Coefficient (95\% Cl) & p Value & Coefficient (95\% CI) & $\mathrm{p}$ Value & Coefficient (95\% CI) & p Value \\
\hline \multicolumn{7}{|l|}{ All children } \\
\hline Minimally adjusted* & $-0.64(-0.83$ to -0.46$)$ & $<0.001$ & $-1.03(-1.23$ to -0.82$)$ & $<0.001$ & $-0.86(-1.22$ to -0.49$)$ & $<0.001$ \\
\hline Fully adjusted $t$ & $-0.17(-0.36$ to 0.02$)$ & 0.086 & $-0.63(-0.84$ to -0.42$)$ & $<0.001$ & $-0.87(-1.28$ to -0.45$)$ & $<0.001$ \\
\hline \multicolumn{7}{|l|}{ Paternal smoking } \\
\hline \multicolumn{7}{|l|}{ Males } \\
\hline \multicolumn{7}{|l|}{ Maternal smoking } \\
\hline Minimally adjusted§ & $-0.57(-0.83$ to -0.31$)$ & $<0.001$ & $-1.04(-1.33$ to -0.76$)$ & $<0.001$ & $-1.02(-1.53$ to -0.51$)$ & $<0.001$ \\
\hline Fully adjusted $\pi$ & $-0.07(-0.34$ to 0.201$)$ & 0.611 & $-0.65(-0.95$ to -0.36$)$ & $<0.001$ & $-1.07(-1.65$ to -0.49$)$ & $<0.001$ \\
\hline \multicolumn{7}{|l|}{ Paternal smoking } \\
\hline Minimally adjusted§ & $-0.72(-0.98$ to -0.47$)$ & $<0.001$ & $-1.01(-1.30$ to -0.73$)$ & $<0.001$ & $-0.68(-1.20$ to -0.16$)$ & 0.010 \\
\hline Fully adjusted $t$ & $-0.28(-0.56$ to -0.01$)$ & 0.043 & $-0.64(-0.94$ to -0.34$)$ & $<0.001$ & $-0.69(-1.28$ to -0.12$)$ & 0.020 \\
\hline \multicolumn{7}{|l|}{ Paternal smoking } \\
\hline Minimally adjusted $\uparrow$ & $-0.42(-0.67$ to -0.17$)$ & 0.001 & $-0.61(-0.89$ to -0.33$)$ & $<0.001$ & $-0.43(-0.93$ to 0.07$)$ & 0.094 \\
\hline Fully adjusted ${ }^{* *}$ & $-0.16(-0.42$ to 0.09$)$ & 0.215 & $-0.32(-0.60$ to -0.03$)$ & 0.029 & $-0.30(-0.85$ to 0.26$)$ & 0.294 \\
\hline
\end{tabular}

${ }^{*}$ Adjusted for child's age at time of height measurement and sex.

†Adjusted for family income, marital status, schooling, age, skin colour, parity, maternal height and BMI, pregnancy duration, child's age at time of height measurement, sex and paternal smoking during pregnancy.

$\ddagger$ Adjusted for family income, marital status, schooling, age, skin colour, parity, height, BMI, pregnancy duration, child’s age at time of height measurement, sex and maternal smoking during pregnancy.

$\S$ Adjusted for child's age at time of height measurement.

TAdjusted for family income, marital status, schooling, age, skin colour, parity, maternal height and BMI, pregnancy duration, child's age at time of height measurement and paternal smoking during pregnancy.

${ }^{* *}$ Adjusted for family income, marital status, schooling, age, skin colour, parity, height, BMI, pregnancy duration, child's age at time of height measurement and maternal smoking during pregnancy.

BMI, body mass index.

low missing data (below $5 \%$ ) for most variables in both cohort studies. However, some methodological difficulties of the study need to be discussed. First, it is possible that different results would have been obtained if all children whose mothers originally enrolled in the 1993 cohort study were included in the analysis instead of only subsamples. However, no differences in maternal smoking during pregnancy or in socioeconomic or maternal characteristics were found between those children who were followed-up in the 1993 cohort and those originally enrolled in the study (data not shown, available on request), providing some reassurance that attrition is unlikely to have biased the results. Second, both maternal and paternal smoking data rely on maternal self-report. Even though the validity of self-reported smoking has been demonstrated in previous studies and would be acceptable for maternal smoking status, ${ }^{32}$ no validation has been carried out in our study for paternal information. However, we might anticipate similar, if not even less, reporting bias for paternal smoking than for maternal smoking in pregnancy, as there is likely to be more social pressure on women than on men to not report smoking during pregnancy. Third, even though anthropometric measurements were performed by trained fieldworkers following standardised procedures, leg length (calculated as the difference between standing height and sitting height) is likely to have some measurement error which could have decreased the precision of estimated associations. Finally, it would have been interesting to study the association between maternal passive smoking during pregnancy and child growth. However, no data were available on whether mothers were exposed to passive smoking during pregnancy (ie, if their partner or other people smoked near the woman at home or at work during pregnancy).

Our findings further emphasise the importance of advising women on smoking cessation, particularly in low- and middle-income countries like Brazil. Women of reproductive age should be advised to stop smoking, preferably before attempting to become pregnant, in order to protect their offspring from impaired linear growth and obesity in childhood with potential permanent consequences in adult life.

\section{CONCLUSIONS}

Previous studies have consistently reported associations between maternal smoking in pregnancy and offspring reduced height as well as overweight/obesity, but have been unable to ascertain whether or not associations are causal. This study explored causality based on three approaches: comparisons between two cohort studies 11 years apart, multiple adjustments for confounders and maternal-paternal smoking comparisons. In addition, the effects of maternal smoking on growth at multiple time points during infancy were explored. Although residual confounding cannot be ruled out, the persisting associations following confounder adjustment, the stronger maternal versus paternal smoking associations, the specificity of the maternal smoking 
associations and the consistency between the 1993 and 2004 Pelotas results strongly suggest a possible causal effect of maternal smoking during pregnancy on offspring impaired linear growth and overweight in childhood via intrauterine mechanisms.

Acknowledgements The authors are extremely grateful to all families who took part in the 1993 and 2004 Pelotas birth cohort studies, and the entire Pelotas cohort team, including interviewers, data clerks, laboratory technicians and volunteers. The authors are grateful to Professors Debbie Lawlor and John Judkin for their helpful feedback in preliminary analyses of this study.

Funding This research was specifically funded by the Brazilian National Research Council (CNPq), grant no. 481010/2009-5. The 1993 and 2004 Pelotas birth cohort studies are currently supported by the Wellcome Trust Initiative entitled 'Major Awards for Latin America on Health Consequences of Population Change', grant entitled 'Implications of early life and contemporary exposures on body composition, human capital, mental health and precursors of complex chronic diseases in three Brazilian cohorts' (grant no. 086974/Z/08/Z). Previous phases of the 1993 cohort study were supported by the European Union and the Fundação de Amparo à Pesquisa do Rio Grande do Sul, Brazil. Previous phases of the 2004 cohort study were supported by WHO (Division of Child and Adolescent Health and Development), the Brazilian National Research Council (CNPq) and the Pastoral da Criança (Catholic non-governmental organisation, Curitiba, Brazil).

\section{Competing interests None.}

Ethics approval This study was conducted with the approval of the Medical Ethics Committee of the Federal University of Pelotas, affiliated with the Brazilian Federal Medical Council.

Provenance and peer review Not commissioned; externally peer reviewed.

\section{REFERENCES}

1. Naeye RL. Influence of maternal cigarette smoking during pregnancy on fetal and childhood growth. Obstet Gynecol 1981;57:18-21.

2. Källén K. Maternal smoking during pregnancy and infant head circumference at birth. Early Hum Dev 2000;58:197-204.

3. Fox NL, Sexton M, Hebel JR. Prenatal exposure to tobacco: I. Effects on physical growth at age three. Int J Epidemiol 1990;19:66-71.

4. Hardy JB, Mellits ED. Does maternal smoking during pregnancy have a long-term effect on the child? Lancet 1972;2:1332-6.

5. Rantakallio P. A follow-up study up to the age of 14 of children whose mothers smoked during pregnancy. Acta Paediatr Scand 1983;72:747-53.

6. Leary S, Davey Smith G, Ness A. Smoking during pregnancy and components of stature in offspring. Am J Hum Biol 2006;18:502-12.

7. Wadsworth ME, Hardy RJ, Paul AA, et al. Leg and trunk length at 43 years in relation to childhood health, diet and family circumstances; evidence from the 1946 national birth cohort. Int J Epidemiol 2002;31:383-90.

8. Barr HM, Streissguth AP, Martin DC, et al. Infant size at 8 months of age: relationship to maternal use of alcohol, nicotine, and caffeine during pregnancy. Pediatrics 1984;74:336-41.

9. Conter V, Cortinovis I, Rogari P, et al. Weight growth in infants born to mothers who smoked during pregnancy. BMJ 1995;310:768-71.
10. Popkin BM, Conde W, Hou N, et al. Is there a lag globally in overweight trends for children compared with adults? Obesity (Silver Spring) 2006;14:1846-53.

11. Nader PR, O'Brien M, Houts R, et al. Identifying risk for obesity in early childhood. Pediatrics 2006;118:e594-601.

12. Leary SD, Smith GD, Rogers IS, et al. Smoking during pregnancy and offspring fat and lean mass in childhood. Obesity (Silver Spring) 2006;14:2284-93.

13. Vik T, Jacobsen G, Vatten L, et al. Pre- and post-natal growth in children of women who smoked in pregnancy. Early Hum Dev 1996;45:245-55.

14. von Kries R, Toschke AM, Koletzko B, et al. Maternal smoking during pregnancy and childhood obesity. Am J Epidemiol 2002;156:954-61.

15. Toschke AM, Koletzko B, Slikker W Jr, et al. Childhood obesity is associated with maternal smoking in pregnancy. Eur J Pediatr 2002:161:445-8.

16. Oken E, Levitan EB, Gillman MW. Maternal smoking during pregnancy and child overweight: systematic review and meta-analysis. Int J Obes (Lond) 2008;32:201-10.

17. Batty GD, Alves JG, Correia J, et al. Examining life-course influences on chronic disease: the importance of birth cohort studies from low- and middle-income countries. An overview. Braz J Med Biol Res 2007:40:1277-86.

18. Victora CG, Hallal PC, Araújo CL, et al. Cohort profile: the 1993 Pelotas (Brazil) birth cohort study. Int J Epidemiol 2008;37:704-9.

19. Barros AJ, da Silva dos Santos I, Victora CG, et al. [The 2004 Pelotas birth cohort: methods and description]. Rev Saude Publica 2006;40:402-13.

20. Barros FC, Victora CG. Epidemiologia da Saúde Infantil: um manual para diagnósticos comunitários. São Paulo: Unicef/Hucitec, 1991.

21. Fenton TR. A new growth chart for preterm babies: Babson and Benda's chart updated with recent data and a new format. BMC Pediatr 2003;3:13.

22. Dubowitz LM, Dubowitz V, Goldberg C. Clinical assessment of gestational age in the newborn infant. J Pediatr 1970;17:1-10.

23. WHO Multicentre Growth Reference Study Group. WHO Child Growth Standards based on length/height, weight and age. Acta Paediatr Suppl 2006; $450: 76-85$

24. Rona RJ, Swan AV, Altman DG. Social factors and height of primary schoolchildren in England and Scotland. J Epidemiol Community Health 1978:32:147-54.

25. Montgomery SM, Bartley MJ, Wilkinson RG. Family conflict and slow growth. Arch Dis Child 1997;77:326-30.

26. Gigante DP, Nazmi A, Lima RC, et al. Epidemiology of early and late growth in height, leg and trunk length: findings from a birth cohort of Brazilian males. Eur J Clin Nutr 2009;63:375-81.

27. Barros AJ, Victora CG, Horta BL, et al. Effects of socioeconomic change from birth to early adulthood on height and overweight. Int J Epidemiol 2006;35:1233-8

28. Victora CG, Adair L, Fall C, et al. Maternal and child undernutrition: consequences for adult health and human capital. Lancet 2008;371:340-57.

29. Li L, Manor 0, Power C. Early environment and child-to-adult growth trajectories in the 1958 British birth cohort. Am J Clin Nutr 2004;80:185-92.

30. Kawakita A, Sato K, Makino H, et al. Nicotine acts on growth plate chondrocytes to delay skeletal growth through the alpha7 neuronal nicotinic acetylcholine receptor. PLOS ONE 2008; 3:e3945.

31. Yanai J, Pick CG, Rogel-Fuchs Y, et al. Alterations in hippocampal cholinergic receptors and hippocampal behaviors after early exposure to nicotine. Brain Res Bull 1992;29:363-8.

32. Patrick DL, Cheadle A, Thompson DC, et al. The validity of self-reported smoking: a review and meta-analysis. Am J Public Health 1994;84:1086-93. 